\title{
Nanostructured 3-D Collagen/Nanotube Biocomposites for Future Bone Regeneration Scaffolds
}

\author{
Edelma E. da Silva', Heloisa H. M. Della Colleta ${ }^{2}$, Andre S. Ferlauto ${ }^{1}$, Roberto L. Moreira', Rodrigo R. \\ Resende $^{1}$, Sergio Oliveira ${ }^{1}$, Gregory T. Kitten ${ }^{2}$, Rodrigo G. Lacerda ${ }^{1}(\bowtie)$, and Luiz O. Ladeira ${ }^{1}$ \\ ${ }^{1}$ Universidade Federal de Minas Gerais, Departamento de Física, Laboratório de Nanomateriais, Av. Antônio Carlos, 6627, 30123-970, \\ Belo Horizonte, MG, Brazil \\ ${ }^{2}$ Universidade Federal de Minas Gerais, Departamento de Morfologia, Av. Antônio Carlos, 6627, 30123-970, Belo Horizonte, MG, Brazil \\ Received: 4 November 2008/Revised: 20 March 2009/Accepted: 20 March 2009 \\ CTsinghua University Press and Springer-Verlag 2009. This article is published with open access at Springerlink.com
}

\begin{abstract}
The field of bionanotechnology has been rapidly growing during the last few years and we can now envision a controllable integration between biological and artificial matter, where new biomimetic structures with a wide range of chemical and physical properties will promote the development of a novel generation of medical devices. In this work we describe a collagen/carbon nanotube composite which has the potential to be used as a scaffold for tissue regeneration. Because this biocomposite incorporates the advantageous properties of both collagen and carbon nanotubes, it has most of the characteristics that an ideal biomaterial requires in order to be used as an osteoinductive agent. This biocomposite is bioresorbable and biodegradable and has the desired mechanical rigidity while maintaining a three-dimensional(3-D) nanostructured surface. Tuned stability and swelling were achieved under fluid environments by varying the amount of carbon nanotubes (CNTs) incorporated into the composite. These variations can dictate the degree of interaction between fibroblastic cells and the biomaterials. Proof-of-concept was shown by performing an in vitro induced mineralization of hydroxylapatite crystals under physiological conditions. Furthermore, the ability to attach biofunctional groups to the CNT walls can open a new road for tissue regeneration since the combination of CNTs with specific growth factors or cellular ligands can create an environment capable of signaling and influencing specific cell functions. Our observations suggest that collagen/carbon nanotube biocomposites will have important uses in a wide range of biotechnological areas.
\end{abstract}

\section{KEYWORDS}

Biomaterials, carbon nanotubes, collagen, tissue engineering, biocompatibility

\section{Introduction}

Bionanotechnology research involving biocomposite substrates has been rapidly developing in recent years and much work now focuses on a controllable integration between biological and artificial matter. One of the major goals in the field is to develop new biomimetic structures with a wide range of chemical and physical properties which will promote fabrication of a novel generation of medical

Address correspondence to rlacerda@fisica.ufmg.br 
devices [1-6]. Especially notable is the application of nanotechnology in biomaterial development and tissue engineering. Such novel biomaterials have the potential to promote paradigm changes and to revolutionize the science and practice of medicine [1]. New advances in bone tissue engineering have motivated the search for new materials that are biocompatible with the different bioactive functions which actually occur in live, growing tissues [1, 2, 7]. The next generation of biomaterials needs to be biodegradable and bioresorbable, characteristics which should allow new tissues to grow in their environment in a naturally controlled manner [1, 8, 9]. These characteristics are of paramount importance because they will help to solve any long-term issues associated with integration of the implant with its surroundings and allow the biomaterial to be completely replaced by non-immunogenic, host-derived tissues. The ideal scaffold also requires sufficient mechanical rigidity and a porous 3-D structure which can provide maximum integration with cells and body fluids, plus have a nanostructured surface which facilitates the adhesion of cells $[1,10,11]$. Additionally, the biomaterials should also be capable of modification so that it contains functional moieties (e.g., growth factors) that promote and stimulate the growth of new tissue. However, even in view of the many recent advancements in biotechnology, the development of a biomimetic scaffold with all of the above characteristics is still a challenge [5].

Since the 1960s, metals and alloys have been used to produce inert bone graft implants. In the 1970s, ceramics and polymers (natural or synthetic) came into use as either bioactive or bioresorbable bone grafts. More recently, a third generation of biomaterials, such as composites and nanocomposites which have enhanced bioactive and bioresorbable properties, has emerged $[1,5,8,12]$. Synthetic polymers have been widely used as a biodegradable material in tissue engineering [13, 14], whereas bio-derived materials, such as collagen, are being increasingly applied in regenerative medicine [5, $15,16]$. The advantages of using a naturally-derived material arise from its biocompatibility and intrinsic biological recognition. For instance, bone can be considered to be a true nanocomposite since its matrix is mainly composed of inorganic (hydroxylapatite, HA) and organic phases (mainly collagen) [5, 9, 15]. The use of collagen as a biomaterial is an obvious choice since it is a biodegradable material, which can be resorbed by the body and cells can directly or indirectly adhere to it. However, its weak mechanical properties have hindered its use in a wide range of tissue engineering applications. As a consequence, much effort has focused on the development of collagen nanocomposites. In particular, collagen and HA nanocomposites have been intensively explored and shown promise as a bone regenerative scaffold $[1,5,15,17-19]$. One can speculate that a major breakthrough in the use of nanotechnology in tissue engineering will occur when tailored nanomaterials with specific biofunctions are combined with naturally derived materials generating a novel scaffold with improved biological characteristics.

Carbon nanotubes (CNTs) are one nanomaterial that has a great potential for applications in bone regeneration [4, 20-23]. Single and multi-walled carbon nanotubes (SWCNTs / MWCNTs) have diameters ranging from $0.7 \mathrm{~nm}$ to about $100 \mathrm{~nm}$ and lengths that can be thousands of times greater. These hollow, cylindrical carbon structures are among the strongest and stiffest materials known [24-26]. It is well established that the addition of small amounts of CNTs into polymers results in composites with improved mechanical and electrical properties [27-30]. Recently, advances in chemical functionalization of carbon nanotubes have made them much more attractive for use in biological applications [23, 31-34]. The ability to attach functional groups on the nanotube surface enables a wide range of possible applications such as biosensors, bio-delivery agents, and scaffolds for cellular growth, among others [35, 36]. Moreover, the ability of nanotubes to act as an osteoinductor has been recently demonstrated [37-39]. In these studies, functionalized CNTs were able to induce the nucleation and growth of HA crystals in vitro under physiological concentrations of $\mathrm{Ca}^{2+}$ and $\mathrm{PO}_{4}{ }^{3-}$. Additionally, the interaction of CNTs with osteoblasts (bone-forming cells) has also been described and good biocompatibility and bone

\section{Springer}


formation have been observed [37-39]. Other work has also shown increased osteoblast alkaline phosphatase activity and calcium deposition when carbon fibers and nanotubes were used as substrates for cell growth and increased osteoblast adhesion when a polyurethane/CNT composite was used as a substrate [20, 22].

Although much recent work has demonstrated that CNTs are a promising material for tissue engineering, nevertheless the lack of self-rigidity of CNTs hinders their application as an implantable biomaterial for bone regeneration. Therefore, in order to achieve the full potential of CNTs as scaffolds, it is crucial to combine them with a suitable matrix. Different biocompatible synthetic polymers such as polyvinyl alcohol (PVA), polymethyl methacrylate (PMMA), polycarbonate urethane (PU), and poly$L$-lactic acid (PLA) have been investigated as composites with CNTs [31-35]. Although these polymers lack mechanical strength, this can be mitigated by the addition of CNTs. In addition, CNTs can be more easily functionalized than such synthetic polymers. The use of natural polymers, however, seems to have a greater potential in tissue engineering. For example, collagen is one of the most common proteins in the connective tissues of vertebrates and plays crucial biological roles in structural maintenance, cell adhesion, cell migration, and tissue integrity and remodeling [40]. Collagens are produced by several cell types in the form of single, helical polypeptide chains (alpha chains), each about 1000 amino acids long, which self-associate into trimeric molecules and then into higher-order, durable fibrils and fibers. Thus, one can envision that the combination of the properties of collagen and CNTs could create a unique biomaterial with improved and novel characteristics. Nevertheless, investigation of the interactions of CNTs with collagen has been restricted to only a few studies [41-46]. CNTs functionalized with collagen molecules have been used to improve the mechanical properties of PVA/CNT composites [46]. MacDonald et al. showed that the presence of carboxylated CNTs in collagen/SWCNT composites did not alter the initial formation of gels containing live smooth muscle cells, nor affect the cell viability or proliferation of these cells. However, they noted that matrices containing $2 \mathrm{wt} \%$ SWCNTs showed a delay in gel compaction during the first three days of the experiment, indicating that CNTs improve the mechanical strength of the biocomposite gel [43]. In recent work, MacDonald et al. used collagen/CNT biocomposites to show that this product can be used as a substrate to study electrical stimulation of cells and can act as a transducer for future biosensors [44, 45]. Cao et al. have described collagen/MWCNT composites which display better mechanical properties than pure collagen [41]. In this work, we describe a biocomposite that incorporates the advantageous properties of both collagen and carbon nanotubes. The collagen/nanotube composite developed here possessed most of the required characteristics that an ideal biomaterial needs in order to be used as an agent of osteoinduction for bone tissue regeneration. The biocomposite was bioresorbable and biodegradable and had the desired mechanical rigidity while maintaining a 3-D nanostructured surface. Tuned stability and swelling were also achieved in fluid environments by varying the amount of CNTs incorporated into the composite. These variations can dictate the degree of interaction between fibroblastic cells and the biomaterial. Proofof-concept was shown by performing an in vitro induced mineralization of hydroxylapatite crystals under physiological conditions. It is clear that such biocomposites could have important applications in a wide range of biotechnological areas.

\section{Experimental}

Carbon nanotube synthesis. SWCNTs were prepared by the arc discharge method using $\mathrm{Co}$ and $\mathrm{Ni}$ as catalysts with helium atmosphere at total pressure 500 Torr [47]. After synthesis, the material was purified by a sequence of thermal oxidation and acid treatments. The purified SWCNTs $(1 \mathrm{~g})$ were refluxed in $\mathrm{HNO}_{3}(3 \mathrm{~mol} / \mathrm{L})$ in a domestic microwave oven for $15 \mathrm{~min}$. After that, the material was centrifuged at $7000 \mathrm{rpm}$ and washed with distilled water. The final solution was dried for $12 \mathrm{~h}$ at $60{ }^{\circ} \mathrm{C}$. The resulting material ( $0.75 \mathrm{~g}$ of high purity) was then functionalized with $\mathrm{COOH}$ groups. A detailed 
description of the functionalization methods as well as the characterization of the CNTs can be found in the Electronic Supplementary Material (ESM).

Collagen extraction. Collagen type I was extracted from rat tails and cattle tendons. The tendons were separated, ground, and washed three times in phosphate buffer saline (PBS) and three times in ethanol $(70 \%)$. Collagen was further extracted in acetic acid $(0.5 \mathrm{~mol} / \mathrm{L})$ overnight and centrifuged $(14,000 \mathrm{~g}, 1 \mathrm{~h})$ to remove vessels and other insoluble particles. The collagen was salt precipitated $(0.7 \mathrm{~mol} / \mathrm{L} \mathrm{NaCl})$, resuspended with acetic acid $(0.5 \mathrm{~mol} / \mathrm{L})$ and extensively dialyzed with acetic acid $(0.02 \mathrm{~mol} / \mathrm{L})$. The final concentration of the stock collagen solution, containing an estimated $97 \%-98 \%$ native type I collagen and $2 \%-3 \%$ type III collagen, was $5.6 \mathrm{mg} / \mathrm{mL}$.

Cells. 3T3 fibroblasts cells were maintained in $25 \mathrm{~cm}^{2}$ tissue culture flasks in Dulbecco's modified Eagle's medium (DMEM) containing fetal bovine serum (FBS, 7\%), penicillin G (100 units $/ \mathrm{mL})$, streptomycin $(100 \mathrm{mg} / \mathrm{mL})$ and amphotericin $B$ $(2.5 \mathrm{mg} / \mathrm{mL})$. 3T3 fibroblasts were chosen for these studies since they can be induced to form bone and will be useful in future models of bone remodeling.

Biocomposite formation. An aqueous solution of collagen $(5.6 \mathrm{mg} / \mathrm{mL})$ was prepared in acetic acid with $\mathrm{pH}$ adjusted to between 2 and 4 . This $\mathrm{pH}$ value had been previously optimized to enable a homogenous dispersion of SWCNTs in the collagen matrix. In parallel, a solution containing $\mathrm{COOH}-$ SWCNTs $(0.5 \mathrm{mg} / \mathrm{mL}, \mathrm{pH}=5)$ was made using an ultrasonic bath. Varying amounts of the SWCNT solution were mixed into the collagen solution at a weight percent (milligrams SWCNT per milligrams collagen) of $0.2 \mathrm{wt} \%, 0.5 \mathrm{wt} \%, 1 \mathrm{wt} \%, 2 \mathrm{wt} \%, 3 \mathrm{wt} \%$, or $4 \mathrm{wt} \%$. Control constructs did not contain any COOH-SWCNTs (0 wt\%). Finally, the $\mathrm{pH}$ of the solution was raised to $\mathrm{pH} 7.2$ using $\mathrm{NaOH}$. In neutral $\mathrm{pH}$ aqueous solution, collagen molecules reassociate into fibrils and form a gel. Solvents were removed by submitting the biocomposite gel to a lyophilization process.

Transmittance measurements. Fourier transform infrared (FTIR) transmission spectra in the midinfrared region $\left(650-4000 \mathrm{~cm}^{-1}\right)$ were collected with a Centaurus microscope attached to a Nicolet-Nexus spectrometer. The samples were prepared by depositing several drops of the biocomposite solutions on undoped Si wafers. Reference spectra were taken in clean regions of the same wafers. The measurements were performed under nitrogen purge, with spectral resolution of $4 \mathrm{~cm}^{-1}$, by averaging 64 scans.

Stress and rupture tension measurements. The composites were subjected to load-deformation analysis using an Instron automated testing system. The experiments were carried out at a constant crosshead speed of $5 \mathrm{~mm} / \mathrm{min}$ with relative humidity of $60 \%$ at $25-32{ }^{\circ} \mathrm{C}$. Before subjecting the samples to analysis, strip shaped samples of uniform width of $10 \mathrm{~mm}$ and thickness about $0.02 \mathrm{~mm}$ were dried in a desiccator. Statistical comparison of the results was determined by one-way ANOVA followed by Bonferroni's test with the level of significance set at $P<0.05$.

Swelling assay. The intumescent coatings were formulated using PBS buffer. A sample was immersed in PBS for an extended period of time and digital pictures taken on a daily basis. The pictures showed marked variation in the sample size and were used to probe the degree of swelling and integrity of the composites.

Gel contraction assay. Biocomposite gels were prepared as described above, but with inclusion of DMEM, FBS and antibiotics in the gel. The $\mathrm{pH}$ was adjusted to 7.2 with $\mathrm{NaOH}$ and $\mathrm{COOH}-\mathrm{SWCNT}$ were added in the following concentrations: $0,0.625$ $w t \%, 1.25 \mathrm{wt} \%$ and $2.5 \mathrm{wt} \%$. Cells were added at a concentration of $2.5 \times 10^{5}$ cells $/ \mathrm{mL}$ and then $1 \mathrm{~mL}$ of the mixture, in triplicate for each CNT concentration, was placed into wells on a 24-well plate. The plates were placed in an incubator at $37{ }^{\circ} \mathrm{C}$, in $5 \% \mathrm{CO}_{2}$. After collagen gelation $(1 \mathrm{~h}), 1 \mathrm{~mL}$ of culture medium was added to each well to maintain the cells during the experiment. In order to allow the cells to contract the gel, the gels were detached from the sides and bottom of the wells and the plates returned to the incubator and kept in culture for 7 days, with changes of medium every other day. Digital images of the gels within the wells were captured daily. The areas of the gels were determined using the Image J program (http://rsb.info.nih.gov/ij/, National 
Institutes of Health, Bethesda, Maryland, USA). Statistical comparison of the results was determined by one-way ANOVA followed by Bonferroni's test with the level of significance set at $P<0.05$.

Mineralization experiments. A composite containing $4 \mathrm{wt} \%$ of $\mathrm{COOH}-\mathrm{SWCNTs}$ was incubated in a vial containing $1 \mathrm{mmol} / \mathrm{L} \mathrm{CaCl}_{2}(2 \mathrm{~mL})$ and 0.5 $\mathrm{mmol} / \mathrm{L} \mathrm{Na}_{2} \mathrm{HPO}_{4}(2 \mathrm{~mL})$. A pure collagen sample was also incubated under the same conditions to be used as a reference. After mineralization for one and four weeks, the samples were taken out of the solution and rinsed carefully and thoroughly with water. The resulting dried samples were examined by scanning electron microscopy.

\section{Results and discussion}

Figures 1(a) and 1(c) show scanning electron micrographs of lyophilized collagen gels produced using collagen from bovine and rat, respectively. Structural changes were observed for composites prepared with $4 \mathrm{wt} \%$ of COOH-SWCNTs when compared with their pure collagen counterparts, see Fig. 1(b) (bovine) and Fig. 1(d) (rat), respectively. The presence of CNTs promoted a decrease in the porosity of the matrix and an enhanced nanostructure surface in the composites formed with both collagen sources, although some structural differences between collagen from rat and cattle were apparent. One of the main goals of developing a collagen/ CNT composite is to improve the poor mechanical properties of collagen, which have hindered a wider application of this molecule in bioengineering. To assess the degree of improvement, stress-strain curves were measured for both types of pure collagen and composites made with $4 \mathrm{wt} \%$ of COOH-SWCNTs (Fig. 2). The mechanical properties (tensile strength) of the composites were superior to those of the pure counterparts for both collagen sources. The pure collagen from rat showed a poor stress resistance and when CNTs were added to the matrix, the stress resistance increased by factor of about three. The pure collagen from bovine was more resistant to stress; the presence of CNTs also increased the resistance of the composite, but to a lower extent as compared to rat collagen. Rupture-tension experiments showed

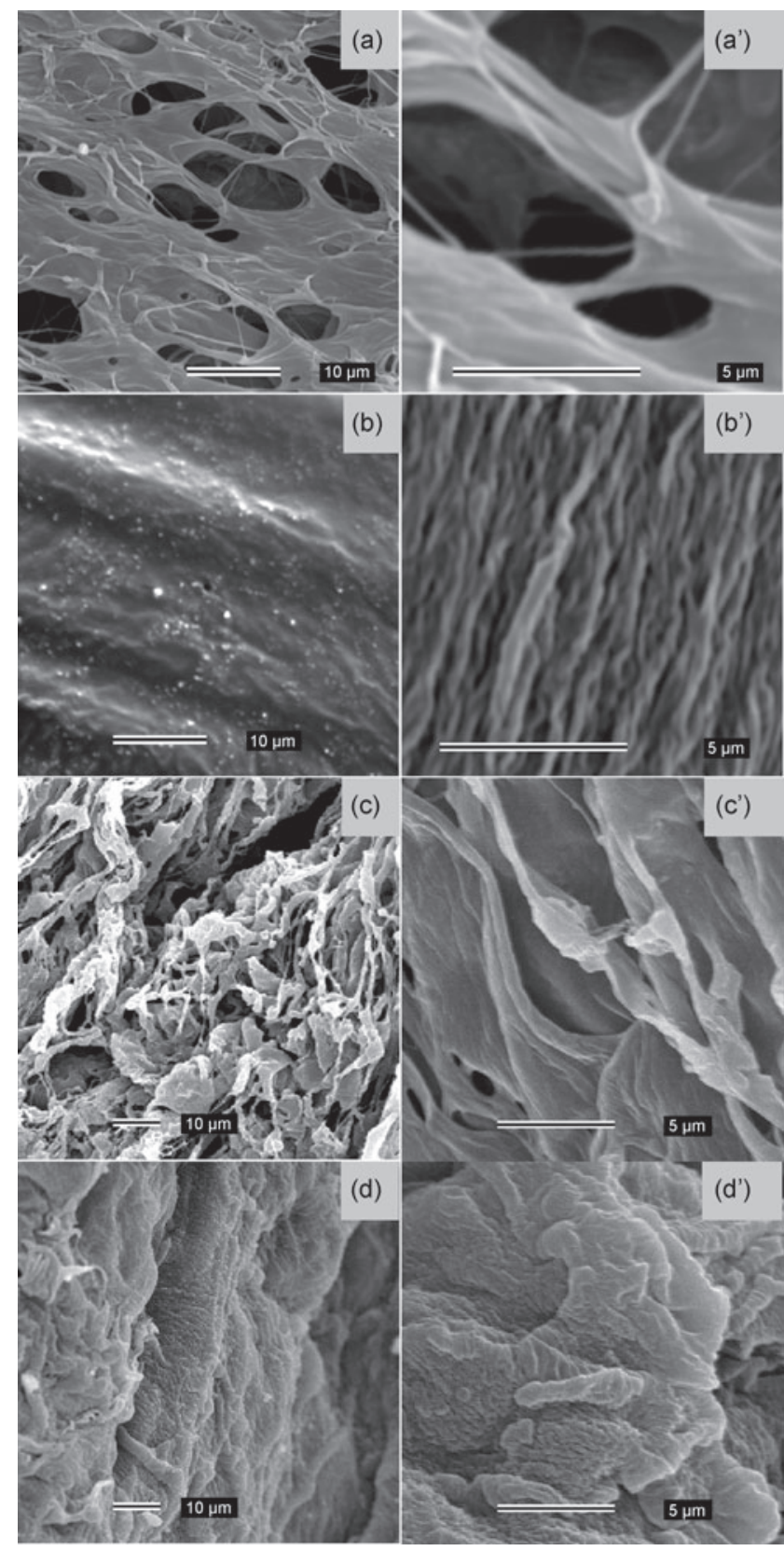

Figure 1 Scanning electron micrographs of pure collagen and collagen/carbon nanotube (CNT) composites: (a) bovine collagen; (b) bovine collagen composite; (c) rat collagen; (d) rat collagen composite. $\left(a^{\prime}\right),\left(b^{\prime}\right),\left(c^{\prime}\right)$, and $\left(d^{\prime}\right)$ show higher magnification images of (a), (b), (c), and (d), respectively

that composites made with rat collagen were more resistant than composites made with bovine collagen. These differences may be attributed to the particular characteristics of each collagen. It is also important to note that the values of the tensile strength obtained were of the same order as those found in Ref. [48]. These results suggest that the collagen from rat tail tendon is more susceptible to improvement due to 


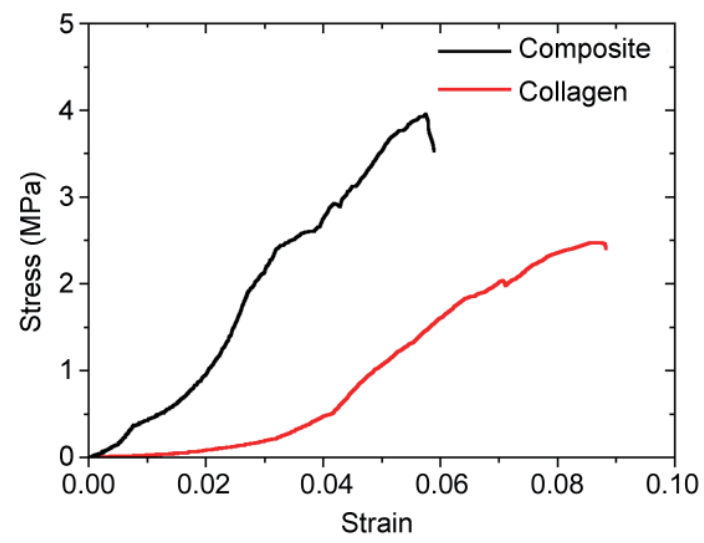

(a)

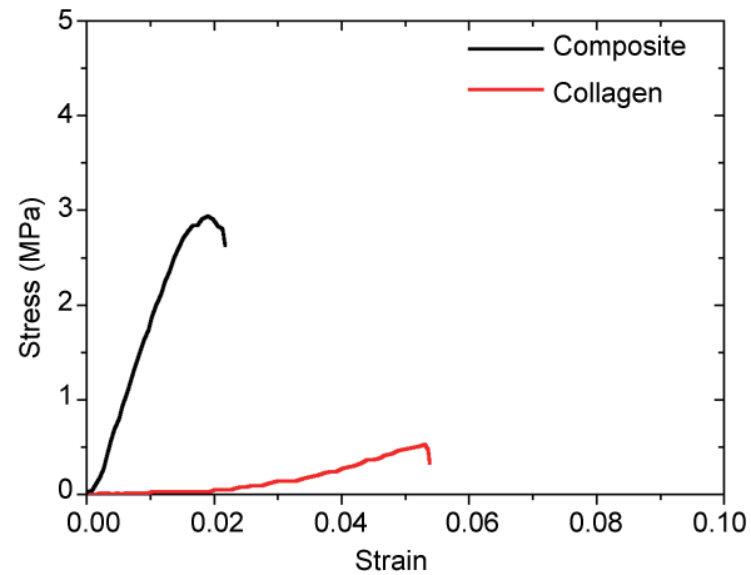

(b)

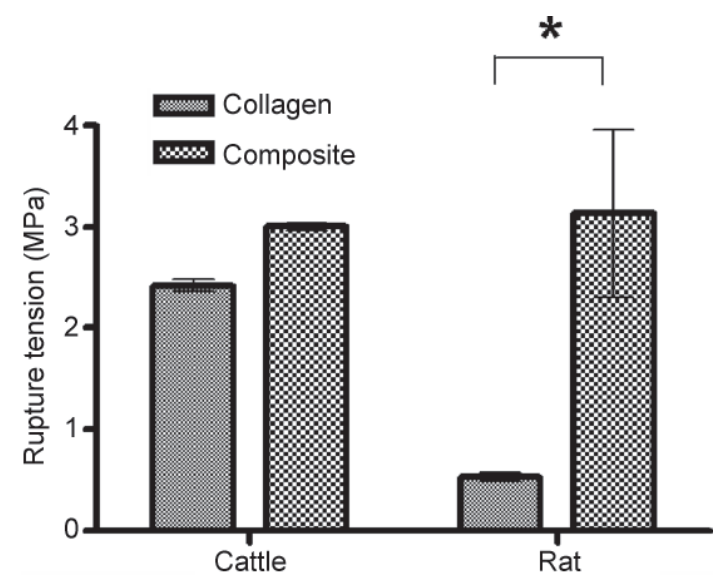

(c)

Figure 2 Stress assay for composite (4 wt\% CNTs) and pure collagen from bovine (a) and rat (b). Rupture-tension assays (c) showed that composite from rat collagen is more resistant than composite made with bovine collagen $(P<0.05)$

CNT incorporation. Thus, we decided to continue the experiments using only the collagen isolated from this source.

To demonstrate the integrity of collagen fibers in the composite, infrared spectroscopy was performed
(Fig. 3). The ratio of the absorbances of the bands at 1235 and $1450 \mathrm{~cm}^{-1}$ can be used as a measurement of the integrity of the collagen triple helix structure. If a ratio of unity is found, collagen triple helices are present $[49,50]$. Using this method we found an intensity ratio of about 0.9 for the collagen prepared by our method (both pure and composite). This confirms that the procedure we applied to prepare the composite did not degrade the collagen molecules. All the peaks observed in the IR are consistent with vibrational modes of the proteins present in the collagen molecule.

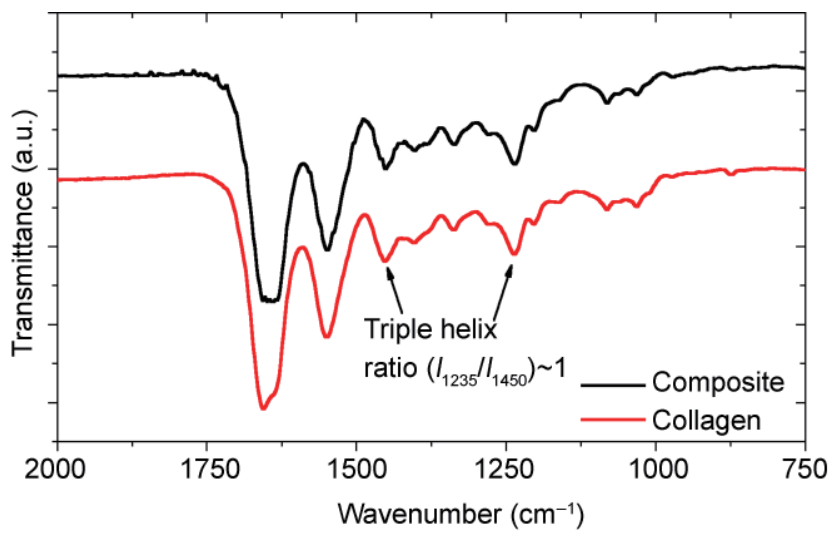

Figure 3 FTIR spectra of pure collagen (red) and composite with CNTs (4 wt \%) (black)

Another aspect that is essential in a biomaterial is its stability under fluid environments. One would expect that a material with tuned stability might have interesting applications in tissue engineering. One way to assess this property is to probe the degree of intumescence (or swelling) of the material. For instance, it is well known that when immersed in a fluid, collagen swells, absorbs and retains large amounts of water [51,52]. Intumescence is a crucial property for tissue regeneration since the extent of this swelling, combined with the stability of the composite in this state will dictate the degree of interaction between the fluid cells and the composite. If, for instance, one has a material with long-term stability and a high degree of swelling, an increased interaction between the cells and the biomaterial would be expected, consequently raising the chances of new tissue growth. Furthermore, ideally after sometime, the biomaterial would be degraded and reabsorbed by the body. Figure 4 shows pictures 
of two composites $(0.2 \mathrm{wt} \%$ and $4 \mathrm{wt} \% \mathrm{COOH}$ SWCNT) immersed in a physiological solution (PBS) for different immersion times (see Fig. S-1 in the ESM for the full set of pictures taken at different times). A picture of a pure collagen sample immersed in a physiological solution is not shown since the material degraded very easily and the solution became transparent. The effect of CNT addition on the composite stability can be indirectly probed by analyzing the general appearance and morphology of the immersed material over time. Analysis of Fig. 4 shows that noticeable changes can be already observed at day 15 for the composite with $0.2 \mathrm{wt} \%$ of CNTs. After this time, the composite started to lose its integrity and break apart. In contrast, the composite with $4 \mathrm{wt} \%$ of CNTs still maintained its expanded structure. The degradation process proceeded continuously for the composite with $0.2 \mathrm{wt} \%$ of CNTs until day 250, by which time the composite had lost most of its structure. Significantly less composite degradation was observed for the composite with the higher amount of CNTs (4 wt\%).

During the entire period of the study this composite was able to maintain its structure, and it only started to lose its form at day 250. These observations indicate that it is possible to control the degree of stability of the composite by altering the amount of CNTs incorporated. Thus, it would be possible to tune the composite for different applications in tissue engineering where shorter or longer times for tissue regeneration are required. This result also suggests that this biomaterial may be of great use not only for tissue engineering but also as a drug delivery agent [36].

(Days)

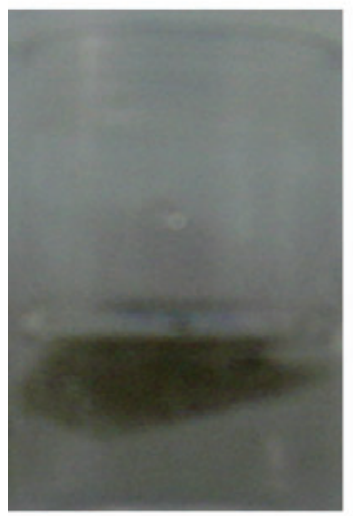

1

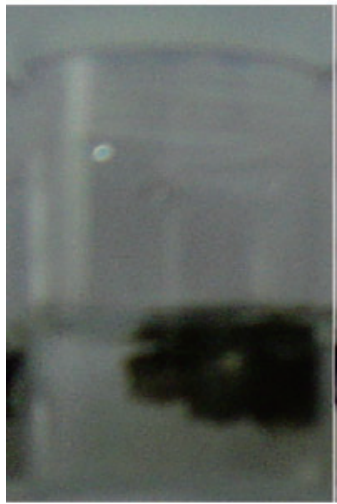

12

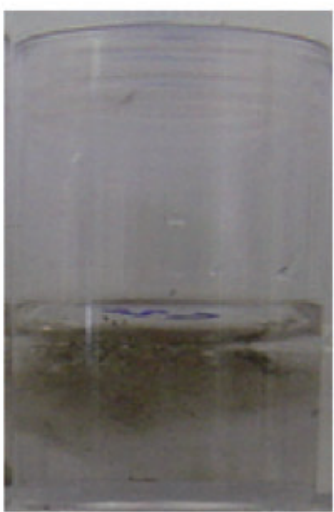

12

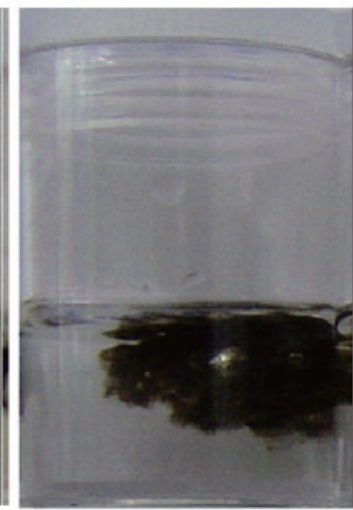

15

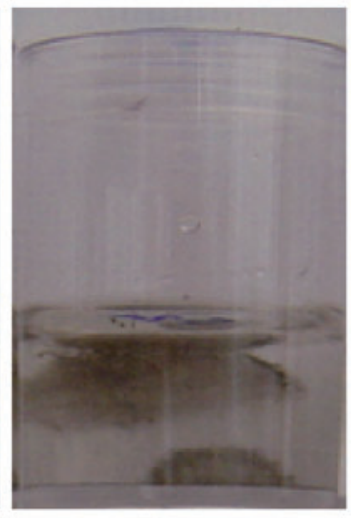

Composite (0.2 wt \% CNT)

15

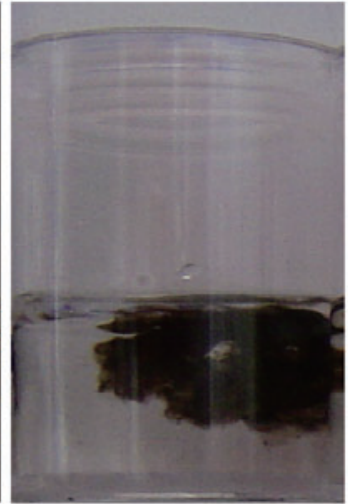

Composite (4 wt \% CNT)
61

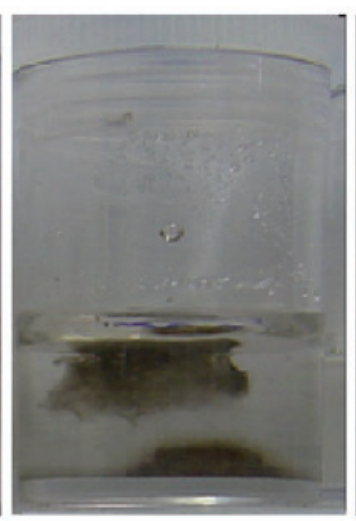

61

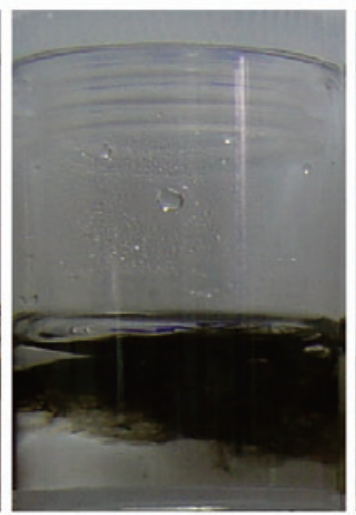

250

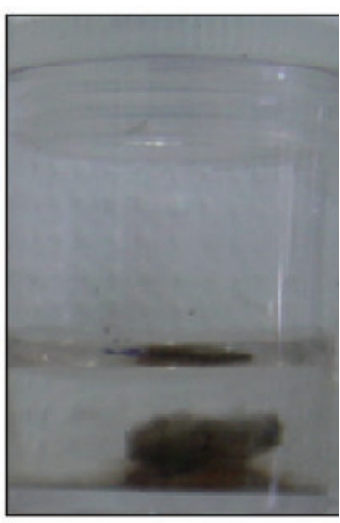

250

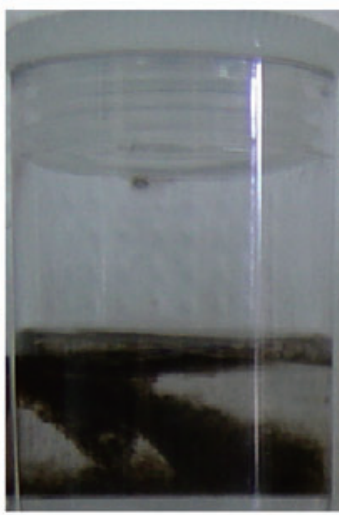

Figure 4 Swelling assay. Composites were lyophilized and then placed in a tube with PBS. Pictures were taken over a 250 day period (the number of days is indicated above each figure). The composites disintegrated at different times, depending on the CNT concentration 
In order to be used as scaffold for bone regeneration, it is important that a biocomposite maintains its original size and its 3-D structure when incorporated inside the body. When fibroblasts are embedded within a collagen gel, they are normally able to contract the gel, decreasing its volume. If the intended use of a biocomposite is to act as a scaffold, contraction should be avoided, since gaps would be formed between the tissue and the composite. The effect of CNTs on fibroblast cells within a collagen gel was investigated by performing a gel contraction assay. The primary goal of this experiment was to determine if the presence of CNTs alters the ability of the fibroblasts to contract the collagen gel and thus allows a structure that could be used as a scaffold to be maintained. The degree of gel contraction was assessed by measuring the sample areas (Fig. 5). We observed that the contraction of the biocomposite by 3T3 cells was diminished in the presence of CNTs. At the end of experiment, the collagen gel without CNTs contracted by $22 \%$, while the collagen gels with $0.625 \mathrm{wt} \%, 1.25 \mathrm{wt} \%$, and $2.5 \mathrm{wt} \%$ CNTs contracted by about $8 \%$. Thus, the presence of CNTs inhibits the collagen gel contraction normally observed with 3T3 cells, but no evidence of a CNT concentration dependence was found. The measured areas showed statistical significance $(P<0.05)$ for almost all groups compared to the control at days 2 to 7 of analysis. The exception was the group with $0.625 \mathrm{wt} \%$ of CNTs at days 2 and 3. Our results are consistent with the idea that CNTs increase gel resistance, and thus the cells are not able to contract the gel. However, in order to validate this assumption, it will be necessary to run cell viability assays to determine whether CNTs are toxic or not, to exclude the possibility that killing of the cells was responsible for contraction of the gel.

Although several studies in the literatures have shown an association between CNTs and collagen, the degree of toxicity of CNTs has not been well defined [39, 53-55]. For instance, MacDonald et al. [43], using aortic smooth muscle cells, showed that constructs containing $2 \mathrm{wt} \%$ CNTs in a $2 \mathrm{mg} / \mathrm{mL}$ collagen gel exhibited delayed gel compaction compared to that observed with lower concentrations of CNTs and to the control (absence of CNTs). Importantly, they also determined that the cell viability was consistently
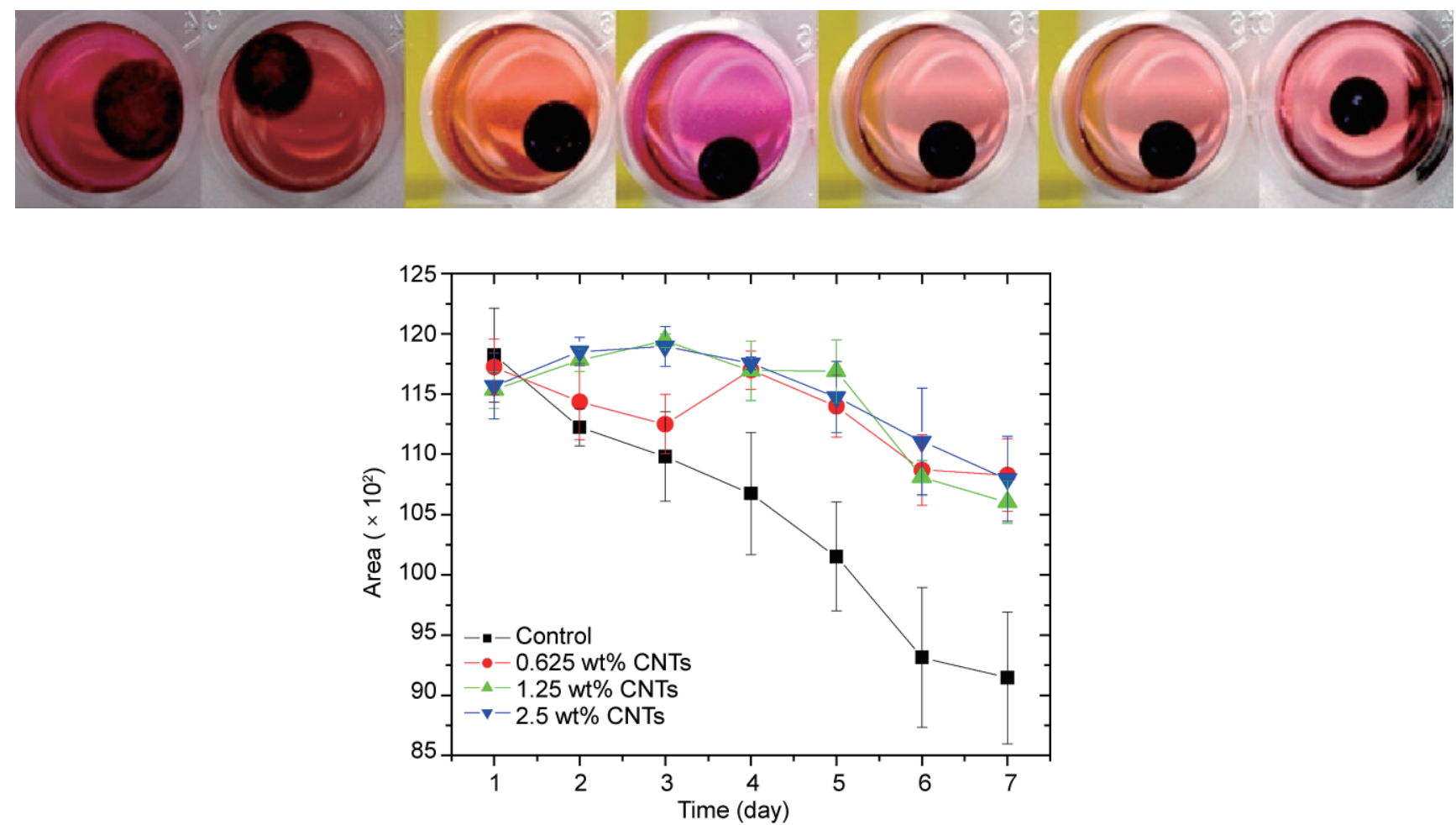

Figure 5 In vitro collagen gel contraction by 3 T3 fibroblast cells in the presence of different CNT concentrations (wt\%). At the top, a representative gel contraction from day 1 to day 7 . At the bottom, the graph shows the gel area measurements obtained with $3 T 3$ cells. The areas were measured as units of squared pixels in the digital images 
above $85 \%$ in all the constructs. Although we did not test the viability of the cells to prove the biocompatibility of the composite, or test the migration of the cells within the gels [42], our results indicate that the composites might have an important biofunctionality, supporting our proposal that they can be used as a scaffold for bone regeneration and other applications in tissue engineering that require the biocomposite to retain its original structure.

Our final experiment was to verify the potential of the collagen/CNT composite as an osteoinductor. We performed mineralization tests of the composite with HA (which is a naturally occurring form of calcium apatite and present as HA crystals in bone tissue) under physiological concentrations of $\mathrm{Ca}^{2+}$ and $\mathrm{PO}_{4}^{3-}$. These types of experiments have already successfully been done on pure CNTs, and demonstrated that CNTs are promising osteoinductors [37-39]. The idea behind these experiments was to assess if the nanocomposite within the body fluid would be able, in contact with small concentrations of $\mathrm{Ca}^{2+}$, to stimulate the formation of HA. Calcium salts in bone provide structural integrity to the skeleton, and they exist largely in the form of hydroxylapatite. The mineralization processes for pure collagen and for the collagen/CNT composite were performed under physiological concentrations of $\mathrm{Ca}^{2+}$ and $\mathrm{PO}_{4}{ }^{3-}$ ions: both materials were immersed in $0.5 \mathrm{mmol} / \mathrm{L} \mathrm{Na}_{2} \mathrm{HPO}_{4}$ and $1 \mathrm{mmol} / \mathrm{L}$ $\mathrm{CaCl}_{2}$ solutions. In parallel, controlled depositions of HA under saturated ( millimolar range) and supersaturated $\left(\sim\right.$ molar range) concentrations of $\mathrm{Ca}^{2+}$ and $\mathrm{PO}_{4}{ }^{3-}$ ions were performed on clean silicon substrates (see Fig. S-2 in the ESM). As expected, no HA deposition was observed by exposing a silicon substrate to concentrations of $\mathrm{Ca}^{2+}$ and $\mathrm{PO}_{4}{ }^{3-}$ ions under physiological concentrations. However, formation of HA crystals was clearly observed for supersaturated concentrations of $\mathrm{Ca}^{2+}$ and $\mathrm{PO}_{4}{ }^{3-}$ ions (Fig. S-2). Thus, this simple experiment demonstrated that it is necessary, under physiological concentrations of $\mathrm{Ca}^{2+}$ and $\mathrm{PO}_{4}^{3-}$ ions, to have nucleation centers present in order to induce the formation of HA crystals. Figure 6 depicts SEM micrographs for pure collagen and composite (4 wt\% of CNTs) after exposure to physiological concentrations of $\mathrm{Ca}^{2+}$ and $\mathrm{PO}_{4}{ }^{3-}$ ions for 1 and 4 weeks. Interestingly, after exposure for 1 week no evidence of HA crystals was found for the pure collagen material, while formation of some HA crystals was clearly observed on the collagen/ CNT composite. After exposure for 4 weeks, both materials were covered with HA crystals (verified by IR spectroscopy - not shown). However, it must be noted that different morphologies were found for the two materials. On the composite, in addition to the formation of HA crystals over the entire composite, we consistently found very large HA crystals (Fig. 6(d)). These results indicate that not only does the nanostructure surface of both materials enable the formation of HA crystals, but also that, qualitatively, an increased induction of HA crystals was observed for the composite. This suggests that the increased mechanical rigidity combined with the enhanced nanostructured character of the composite are the
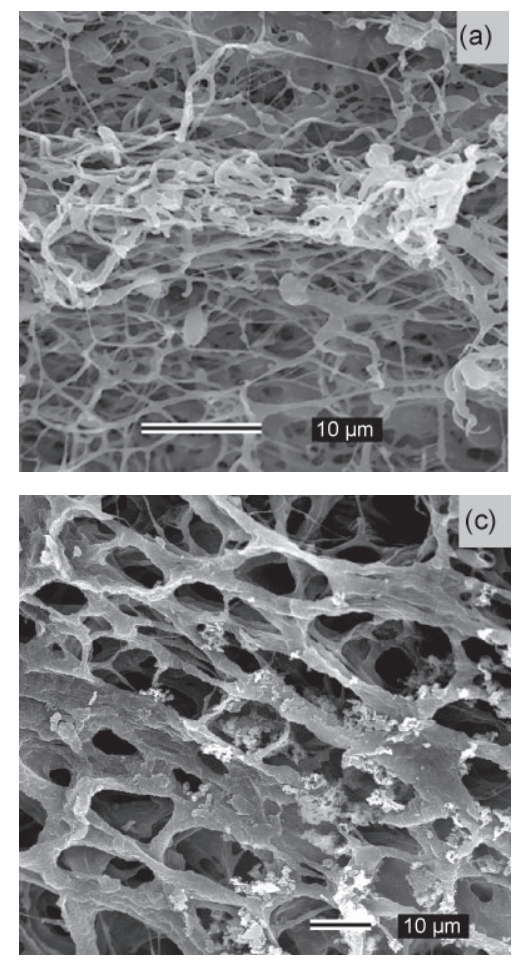

Figure 6 Scanning electron microscopy analysis of HA formation on collagen alone or on collagen composite after 1 and 4 weeks: (a) 1 week, collagen; (b) 4 weeks, collagen; (c) 1 week, collagen composite; (d) 4 weeks, collagen composite 
traits responsible for this improved performance.

To date, very little is known about the interaction between these two species. Based on our results, it appears that CNTs can be incorporated into collagen fibrils during the initial interaction between the dispersed/solubilized collagen and CNTs in an aqueous medium. When collagen fibrillogenesis is initiated, CNTs may become incorporated into the triple-helical collagen molecule, or may remain as a separate phase linking the collagen fibers. It is likely that the carboxyl and hydroxyl groups present on the surface of CNTs can form covalent and hydrogen bonds with amino groups extending from the collagen chains [41, 43]. However, further theoretical and experimental work still needs to be performed to clarify these assumptions.

\section{Conclusions}

A collagen/nanotube composite which has the potential to serve as a scaffold for tissue regeneration has been obtained. The biofunctionality (shape maintenance) associated with this biocomposite and the observation that the composite induces mineralization of HA crystals in vitro opens a wide range of new possibilities concerning its use for the tissue engineering of bone. In vivo tests are now necessary to further confirm the biocompatibility and tissue regeneration characteristics of the composite. This scaffold may not only be biocompatible and biofunctional but also be bioactive and biodegradable. The nanostructure characteristics of the composite have the potential to promote osteoinduction which stimulates the growth of new bone tissue as well as providing a suitable interface between the native bone and the implant. In addition, the ability to attach biofunctional groups to the CNT walls will open a new avenue for tissue regeneration, since the combination of CNTs with specific growth factors or cellular ligands [1] can create a perfect environment to signal and influence specific or key cell functions.

\section{Acknowledgements}

This work was supported by Fapemig, Pronex, Instituto do Milenio/CNPq-MCT, Rede Nano and Instituto Nacional de Ciência e Tecnologia de Nanomateriais de Carbono. R. G. L, A. S. F., R. L. M, S. O., G. T. K., and L. O. L., R. R. R, are CNPq fellows. H. H. M. D. C. is a CAPES fellow.

Electronic Supplementary Material: Supplementary material (five figures and details of growth, purification process, and chemical functionalization of CNTs) is available in the online version of this article at http://dx.doi.org/10.1007/s12274-009-9042-7 and is accessible free of charge.

\section{References}

[1] Greco, R.; Prinz, F.; Smith, R. Nanoscale Technology in Biological Systems, 1st edn.; CRC Press: Boca Raton, Florida USA, 2004.

[2] Sarikaya, M.; Tamerler, C.; Jen, A. K. Y.; Schulten, K.; Baneyx, F. Molecular biomimetics: Nanotechnology through biology. Nat. Mater. 2003, 2, 577-585.

[3] Wagner, V.; Dullaart, A.; Bock, A. K.; Zweck, A. The emerging nanomedicine landscape. Nat. Biotechnol. 2006, 24, 1211-1217.

[4] Liu, H. A.; Webster, T. J. Nanomedicine for implants: A review of studies and necessary experimental tools. Biomaterials 2007, 28, 354-369.

[5] Murugan, R.; Ramakrishna, S. Development of nanocomposites for bone grafting. Compos. Sci. Technol. 2005, 65, 2385-2406

[6] Friess, W. Collagen-Biomaterial for drug delivery. Europ. J. Pharm. Biopharm. 1998, 45, 113-136.

[7] Taton, T. A. Nanotechnology-Boning up on biology. Nature 2001, 412, 491-492.

[8] Hench, L. L.; Polak, J. M. Third-generation biomedical materials. Science 2002, 295, 1014-1017.

[9] Lutolf, M. P.; Hubbell, J. A. Synthetic biomaterials as instructive extracellular microenvironments for morphogenesis in tissue engineering. Nat. Biotechnol. 2005, 23, 47-55.

[10] Moutos, F. T.; Freed, L. E.; Guilak, F. A biomimetic threedimensional woven composite scaffold for functional tissue engineering of cartilage. Nat. Mater. 2007, 6, 162 $-167$.

[11] Stevens, M. M.; George, J. H. Exploring and engineering the cell surface interface. Science 2005, 310, 11351138. 
[12] Hing, K. A. Bone repair in the twenty-first century: Biology, chemistry or engineering? Philos. Trans. R. Soc. Lond. Ser. A-Math. Phys. Eng. Sci. 2004, 362, 2821-2850.

[13] Freed, L. E.; Vunjaknovakovic, G.; Biron, R. J.; Eagles, D. B.; Lesnoy, D. C.; Barlow, S. K.; Langer, R. Biodegradable polymer scaffolds for tissue engineering. Biotechnology 1994, 12, 689-693.

[14] Hubbell, J. A. Biomaterials in tissue engineering. Biotechnology 1995, 13, 565-576.

[15] Wahl, D. A.; Czernuszka, J. T. Collagen-hydroxyapatite composites for hard tissue repair. Eur. Cells Mater. 2006, 11, 43-56.

[16] Wahl, D. A.; Sachlos, E.; Liu, C. Z.; Czernuszka, J. T. Controlling the processing of collagen-hydroxyapatite scaffolds for bone tissue engineering. J. Mater. Sci. -Mater. Med. 2007, 18, 201-209.

[17] Itoh, S.; Kikuchi, M.; Koyama, Y.; Takakuda, K.; Shinomiya, K.; Tanaka, J. Development of an artificial vertebral body using a novel biomaterial, hydroxyapatite/ collagen composite. Biomaterials 2002, 23, 3919-3926.

[18] Kikuchi, M.; Itoh, S.; Ichinose, S.; Shinomiya, K.; Tanaka, J. Self-organization mechanism in a bone-like hydroxyapatite/collagen nanocomposite synthesized in vitro and its biological reaction in vivo. Biomaterials 2001, 22, 1705-1711.

[19] Yunoki, S.; Ikoma, T.; Monkawa, A.; Ohta, K.; Tanaka, J. J. Preparation and characterization of hydroxyapatite/ collagen nanocomposite gel. Nanosci. Nanotechnol. 2007, 7, 818-821.

[20] Price, R. L.; Waid, M. C.; Haberstroh, K. M.; Webster, T. J. Selective bone cell adhesion on formulations containing carbon nanofibers. Biomaterials 2003, 24, 1877-1887.

[21] Sato, M.; Webster, T. J. Nanobiotechnology: Implications for the future of nanotechnology in orthopedic applications. Expert Rev. Med. Devices 2004, 1, 105-114.

[22] Elias, K. L.; Price, R. L.; Webster, T. J. Enhanced functions of osteoblasts on nanometer diameter carbon fibers. Biomaterials 2002, 23, 3279-3287.

[23] Bianco, A.; Prato, M. Can carbon nanotubes be considered useful tools for biological applications? Adv. Mater. 2003, 15, 1765-1768.

[24] Ajayan, P. M. Nanotubes from carbon. Chem. Rev. 1999, 99, 1787-1799.

[25] Endo, M.; Hayashi, T.; Kim, Y. A.; Terrones, M.; Dresselhaus, M. S. Synthesis and application of carbon nanotubes. Chim. Oggi-Chem. Today 2005, 23, 16.
[26] Terrones, M. Controlled production of aligned-nanotube bundles. Nature 1997, 388, 52-55.

[27] Coleman, J. N.; Khan, U.; Blau, W. J.; Gun'ko, Y. K. Small but strong: A review of the mechanical properties of carbon nanotube-polymer composites. Carbon 2006, 44, 1624-1652.

[28] Pasquali, M. Swell properties and swift processing. Nat. Mater. 2004, 3, 509-510.

[29] Thostenson, E. T.; Ren, Z. F.; Chou, T. W. Advances in the science and technology of carbon nanotubes and their composites: A review. Compos. Sci. Technol. 2001, 61, 1899-1912.

[30] Breuer, O.; Sundararaj, U. Big returns from small fibers: A review of polymer/carbon nanotube composites. Polym. Compos. 2004, 25, 630-645.

[31] Banerjee, S.; Hemraj-Benny, T.; Wong, S. S. Covalent surface chemistry of single-walled carbon nanotubes. Adv. Mater. 2005, 17, 17-29.

[32] Georgakilas, V.; Tagmatarchis, N.; Pantarotto, D.; Bianco, A.; Briand, J. P.; Prato, M. Amino acid functionalisation of water soluble carbon nanotubes. Chem. Commun 2002, 3050-3051.

[33] Tasis, D.; Tagmatarchis, N.; Georgakilas, V.; Prato, M. Soluble carbon nanotubes. Chem. -Eur. J. 2003, 9, 4001 -4008 .

[34] Shim, M.; Kam, N. W. S.; Chen, R. J.; Li, Y. M.; Dai, H. J. Functionalization of carbon nanotubes for biocompatibility and biomolecular recognition. Nano Lett. 2002, 2, 285-288.

[35] Pastorin, G.; Wu, W.; Wieckowski, S.; Briand, J. P.; Kostarelos, K.; Prato, M.; Bianco, A. Double functionalisation of carbon nanotubes for multimodal drug delivery. Chem. Commun. 2006, 1182-1184.

[36] Kostarelos, K.; Lacerda, L.; Pastorin, G.; Wu, W.; Wieckowski, S.; Luangsivilay, J.; Godefroy, S.; Pantarotto, D.; Briand, J. P.; Muller, S.; Prato, M.; Bianco, A. Cellular uptake of functionalized carbon nanotubes is independent of functional group and cell type. Nat. Nanotechnol. 2007, 2, 108-113.

[37] Zhao, B.; Hu, H.; Mandal, S. K.; Haddon, R. C. A bone mimic based on the self-assembly of hydroxyapatite on chemically functionalized single-walled carbon nanotubes. Chem. Mater. 2005, 17, 3235-3241.

[38] Zanello, L. P.; Zhao, B.; Hu, H.; Haddon, R. C. Bone cell proliferation on carbon nanotubes. Nano Lett. 2006, 6, 562-567. 
[39] Usui, Y.; Aoki, K.; Narita, N.; Murakami, N.; Nakamura, I.; Nakamura, K.; Ishigaki, N.; Yamazaki, H.; Horiuchi, H.; Kato, H.; Taruta, S.; Kim, Y. A.; Endo, M.; Saito, N. Carbon nanotubes with high bone-tissue compatibility and bone-formation acceleration effects. Small 2008, 4, 240-246.

[40] Myllyharju, J.; Kivirikko, K. I. Collagens, modifying enzymes and their mutations in humans, flies and worms. Trends Genet. 2004, 20, 33-43.

[41] Cao, Y.; Zhou, Y. M.; Shan, Y.; Ju, H. X.; Xue, X. J. Preparation and characterization of grafted collagenmultiwalled carbon nanotubes composites. J. Nanosci. Nanotechnol. 2007, 7, 447-451.

[42] Crouzier, T.; Nimmagadda, A.; Nollert, M. U.; McFerridge, P. S. Modification of single walled carbon nanotube surface chemistry to improve aqueous solubility and enhance cellular interactions. Langmuir 2008, 24, 13173 $-13181$.

[43] MacDonald, R. A.; Laurenzi, B. F.; Viswanathan, G.; Ajayan, P. M.; Stegemann, J. P. Collagen-carbon nanotube composite materials as scaffolds in tissue engineering. J. Biomed. Mater. Res. A 2005, 74A, 489496.

[44] MacDonald, R. A.; Voge, C. M.; Kariolis, M.; Stegemann, J. P. Carbon nanotubes increase the electrical conductivity of fibroblast-seeded collagen hydrogels. Acta Biomat. 2008, 4, 1583-1592.

[45] Voge, C. M.; Kariolis, M.; MacDonald, R. A.; Stegemann, J. P. Directional conductivity in SWNT-collagen-fibrin composite biomaterials through strain-induced matrix alingment. J. Biomed. Mater. Res. A 2008, 86A, 269277.

[46] Bhattacharyya, S.; Salvetat, J. P.; Saboungi, M. L. Reinforcement of semicrystalline polymers with collagenmodified single walled carbon nanotubes. Appl. Phys. Lett. 2006, 88, 223119.
[47] Trigueiro, J. P. C.; Silva, G. G.; Lavall, R. L.; Furtado, C. A.; Oliveira, S.; Ferlauto, A. S.; Lacerda, R. G.; Ladeira, L. O.; Liu, J. W.; Frost, R. L.; George, G. A. Purity evaluation of carbon nanotube materials by thermogravimetric, TEM, and SEM methods. J. Nanosci. Nanotechnol. 2007, 7, 3477-3486.

[48] Veld, P. J.; Stevens, M. Simulation of the mechanical strength of a single collagen molecule. J. Biophys. J. 2008, 95, 33-39.

[49] Sylvester, M. F.; Yannas, I. V.; Salzman, E. W.; Forbes, M. J. Collagen banded fibril structure and the collagen-platelet reaction. Thromb. Res. 1989, 55, 135-148.

[50] Payne, K. J.; Veis, A. Fourier-transform IR spectroscopy of collagen and gelatin solutions-deconvolution of the amide I-band for conformational studies. Biopolymers 1988, 27, 1749-1760.

[51] Huang, C. Y.; Mow, V. C.; Ateshian, G. A. The role of flow-independent viscoelasticity in the biphasic tensile and compressive responses of articular cartilage. J. Biomechan. Eng. -Trans. 2001, 123, 410-417.

[52] Fyhrie, D. P.; Barone, J. R. Polymer dynamics as a mechanistic model for the flow-independent viscoelasticity of cartilage. J. Biomechan. Eng. -Trans. 2003, 125, 578-584.

[53] Kolosnjaj, J.; Szwarc, H.; Moussa, F. Toxicity studies of carbon nanotubes. Adv. Exp. Med. Biol. 2007, 620, 181204.

[54] Raja, P. M. V.; Connolley, J.; Ganesan, G. P.; Ci, L. J.; Ajayan, P. M.; Nalamasu, O.; Thompson, D. M. Impact of carbon nanotube exposure, dosage and aggregation on smooth muscle cells. Toxicol. Lett. 2007, 169, 51-63.

[55] Chou, C. C.; Hsiao, H. Y.; Hong, Q. S.; Chen, C. H.; Peng, Y. W.; Chen, H. W.; Yang, P. C. Single-walled carbon nanotubes can induce pulmonary injury in mouse model. Nano Lett. 2008, 8, 437-445. 